\title{
An evolutionary explanation of the value premium puzzle
}

\section{Journal Article}

Author(s):

Hens, Thorsten; Lensberg, Terje; Schenk-Hoppe, Klaus Reiner; Wöhrmann, Peter

Publication date:

2011-12

Permanent link:

https://doi.org/10.3929/ethz-b-000041061

Rights / license:

In Copyright - Non-Commercial Use Permitted

Originally published in:

Journal of Evolutionary Economics 21(5), https://doi.org/10.1007/s00191-010-0213-1 


\title{
An evolutionary explanation of the value premium puzzle
}

\author{
Thorsten Hens • Terje Lensberg • \\ Klaus Reiner Schenk-Hoppé • Peter Wöhrmann
}

Published online: 29 December 2010

(C) Springer-Verlag 2010

\begin{abstract}
As early as 1934 Graham and Dodd conjectured that excess returns from value investment originate from a tendency of stock prices to converge towards a fundamental value. This paper confirms their insights within the evolutionary finance model of Evstigneev et al. (Econ Theory 27:449-468, 2006). Our empirical results show the predictive power of the evolutionary benchmark valuation for the relative market capitalization and its dynamics in the sample of firms listed in the Dow Jones Industrial Average index in 1981-2009.
\end{abstract}

\section{T. Hens ( $\square)$}

Swiss Banking Institute, University of Zurich,

Plattenstrasse 32, 8032 Zürich, Switzerland

e-mail: thens@isb.uzh.ch

\section{T. Lensberg}

Department of Finance and Management Science,

Norwegian School of Economics and Business

Administration, Bergen, Norway

e-mail: terje.lensberg@nhh.no

K. R. Schenk-Hoppé

Leeds University Business School and School of Mathematics,

University of Leeds, Leeds LS2 9JT, UK

e-mail: k.r.schenk-hoppe@leeds.ac.uk

P. Wöhrmann

Swiss Federal Institute of Technology Zurich,

Kreuzplatz 5, 8032 Zürich, Switzerland

e-mail: pwoehrmann@ethz.ch 
Keywords Value premium • Evolutionary finance

JEL Classification G12 • D53

\section{Introduction}

It is an empirically robust finding that value portfolios (i.e. portfolios with high value-to-price ratio) generate significantly higher returns than those with low value-to-price ratios. Practitioners often assign the latter class of assets colorful names such as growth, momentum or glamor portfolios.

This observation is a puzzle within the Capital Asset Pricing Model (CAPM) because the betas of value portfolios may even be smaller than those of growth portfolios. Starting with Basu $(1977,1983)$, the so-called value premium puzzle has been confirmed by empirical studies of different stock markets and time periods, e.g. Campbell (1999), Davis et al. (2000), Fama and French (1992) and Lettau and Wachter (2007). For instance, Lettau and Wachter (2007) analyzed monthly data from 1952 to 2002 . They find an excess return of value over growth portfolios of about $4.01 \%$ p.a. when value is defined by the dividendprice-ratio. Even higher excess returns are found for other value criteria: For the earnings-price-ratio the excess return is $9.31 \%$ p.a., for the cash flow-priceratio it is $8.04 \%$ p.a., and for the book to market-ratio it is $5.63 \%$ p.a. For all four value criteria the CAPM-betas of value portfolios are not higher and many times even smaller than those of growth portfolios, see (Lettau and Wachter 2007, Table III).

Our aim is to apply the evolutionary finance approach of Evstigneev et al. $(2006,2008)$ to the study of the value premium puzzle. We argue that, as originally claimed by Graham and Dodd (1934), excess returns from value investment stem from a tendency of asset prices to converge toward their fundamental value. Value investment works because financial markets may be temporarily displaced from the long-run fundamental equilibrium but find their way back. This convergence property gives rise to a predictability of asset returns based on fundamental criteria such as the dividend yield. In the evolutionary stock market model of Evstigneev et al. (2006, 2008), the convergence of asset prices stems from the wealth dynamics among heterogenous strategies interacting in the financial markets. Their main finding is that a particular investment strategy is selected by the market (as the long-term outcome of this wealth dynamics) which, in turn, provides an asset pricing benchmark. This benchmark predicts that the relative market value of a firm (relative to the total market value) is equal to the expected discounted relative dividend payments. The strategy of holding assets in proportions equal to their expected relative dividends is the unique evolutionary stable strategy (ensuring longterm survival and domination): Any mutant strategy entering the market will eventually lose its wealth to this incumbent investor. The effect on the asset price dynamics is that the market value of firms reverts to the benchmark in the long-term. The evolutionary model, in combination with the results obtained 
in this framework, offers a novel approach to the study of the value premium puzzle.

By its very nature an evolutionary model has a long-term perspective. Thus our explanation of the value puzzle fits to recent explanations put forward by Lettau and Wachter (2007) and by Hansen et al. (2008) who show that the cash flows of value portfolios have a high duration and co-move with long-term risk like fluctuations in GDP-growth.

Two predictions derived from evolutionary finance will be tested empirically in this paper. The data sample consists of the Dow Jones Industrial Average (DJIA) index during the time period 1979-2009. The first hypothesis is concerned with pricing of firms in cross sections. We claim that our benchmark valuation has predictive power for the relative value of firms in any given year in the sample. The second hypothesis states that asset prices converge to this benchmark over time. If both predictions have strong empirical support, then the value premium puzzle ceases being a puzzle from an evolutionary perspective. Indeed, this is the case as we show in this paper.

The paper is organized as follows. Section 2 briefly reviews the underlying evolutionary model and the relevant results on evolutionary stable investment strategies. Section 3 shows how to justify the findings as an equilibrium in a standard asset pricing model (without out-of-equilibrium dynamics). Section 4 derives the implications for the value premium puzzle and presents the empirical results. Section 5 concludes.

\section{Evolutionary stable markets}

We consider a financial market with $I \geq 1$ investors and $K \geq 1$ long-lived assets (stocks). Asset $k, k=1, \ldots, K$, pays a random dividend $D_{k, t}=D_{k}\left(s_{t}\right) \geq 0$ at time $t=0,1, \ldots$. Dividend payoffs are determined by the state of nature $s_{t} \in S$ (where $S$ is a finite set). Each asset is assumed to be in unit supply. This is without loss of generality and facilitates the presentation: The asset prices in the model will correspond to the market values of firms. The dividend is not reinvested and plays the role of a perishable consumption good as in Lucas (1978).

Normalizing the price of the consumption good to one in all periods in time, an investor's wealth in terms of this numeraire is given by

$$
w_{t+1}^{i}=\sum_{k=1}^{K}\left(D_{k, t+1}+P_{k, t+1}\right) \theta_{k, t}^{i}
$$

where $\left(\theta_{1, t}^{i}, \ldots, \theta_{K, t}^{i}\right)$ denotes investor $i$ 's portfolio $(i=1, \ldots, I)$ and $P_{k, t}$ is asset $k$ 's price in period $t(k=1, \ldots, K)$. Investor $i$ 's portfolio holdings in asset $k$ and the price of each asset $k$ are determined by

$$
\theta_{k, t}^{i}=\frac{\lambda_{k, t}^{i} w_{t}^{i}}{P_{k, t}} \quad \text { and } \quad P_{k, t}=\sum_{i=1}^{I} \lambda_{k, t}^{i} w_{t}^{i}
$$


where $\lambda_{k, t}^{i}$ is investor $i$ 's budget share assigned to the purchase of asset $k$. Prices are determined by equating each asset's market value with the investment in that asset. Note that at these prices demand is equal to supply because $\theta_{k, t}^{1}+\ldots+\theta_{k, t}^{I}=1$ (recall that supply is normalized to one). An investment strategy is formally defined as measurable functions $\lambda_{t}^{i}\left(s^{t}\right)=$ $\left(\lambda_{0, t}^{i}\left(s^{t}\right), \lambda_{1, t}^{i}\left(s^{t}\right), \ldots, \lambda_{K, t}^{i}\left(s^{t}\right)\right)$ with $\lambda_{t}^{i}\left(s^{t}\right) \geq 0$ and $\sum_{k=0}^{K} \lambda_{t}^{i}\left(s^{t}\right)=1$, where $s^{t}=$ $\left(s_{t}, s_{t-1}, \ldots, s_{0}\right)$ is the history of states up to time $t$.

So far we made no assumptions other than those of Lucas (1978). But we have written his model in a way that is more suitable for our analysis. Our first assumption over and above the Lucas model is that all investors consume the same constant fraction $\lambda_{0}>0$ of their wealth in all periods in time, i.e., $\lambda_{0, t}^{i}\left(s^{t}\right) \equiv \lambda_{0}$. This assumption is hard to justify when investors' portfolio strategies $\lambda$ are generated by intertemporal utility maximization since the consumption rate would then be endogenous and fluctuating with the asset returns. However, focussing on the long run survival, as we one does in an evolutionary model, this assumption is paramount since those investors with on average higher consumption rates would easily be driven out by those who consume less. Thus without this assumption nothing can be learned about the evolutionary fitness of portfolio strategies which is the question we address in this paper.

One has (using Eqs. 1 and 2 and the fact that $\lambda_{0}=1-\sum_{k} \lambda_{k, t}^{i}$ for each $i$ ):

$$
\sum_{k=1}^{K} D_{k, t}=: D_{t}=\lambda_{0} W_{t}
$$

where

$$
W_{t}=\sum_{i=1}^{I} w_{t}^{i}
$$

The dynamics of the investors' wealth shares $r_{t}^{i}=w_{t}^{i} / W_{t}$ can be derived from Eqs. 1, 2 and 3:

$$
r_{t+1}^{i}=\sum_{k=1}^{K}\left(\lambda_{0} d_{k, t+1}+\sum_{j=1}^{I} \lambda_{k, t+1}^{j} r_{t+1}^{j}\right) \frac{\lambda_{k, t}^{i} r_{t}^{i}}{\sum_{j=1}^{I} \lambda_{k, t}^{j} r_{t}^{j}}
$$

where $d_{k, t+1}=D_{k, t+1} / D_{t+1}$ denotes asset $k$ 's relative dividend payoff. It is assumed that at least one asset pays a dividend, $D_{t+1}>0$. The last equation is linear in $r_{t+1}=\left(r_{t+1}^{1}, \ldots, r_{t+1}^{I}\right)$. Its solution is given by

$$
r_{t+1}=\lambda_{0}\left(\operatorname{Id}-\left[\frac{\lambda_{k, t}^{i} r_{t}^{i}}{\sum_{i} \lambda_{k, t}^{i} r_{t}^{i}}\right]_{i}^{k} \Lambda_{t+1}\right)^{-1}\left[\sum_{k=1}^{K} d_{k, t+1} \frac{\lambda_{k, t}^{i} r_{t}^{i}}{\sum_{i} \lambda_{k, t}^{i} r_{t}^{i}}\right]_{i}
$$

where $\Lambda_{t+1}^{T}=\left(\lambda_{1, t+1}^{T}, \ldots, \lambda_{K, t+1}^{T}\right) \in \mathbb{R}^{I \times K}$ denotes the matrix of budget shares in period $t+1$. The relative price of asset $k$ is given by $p_{k, t}=\sum_{i=1}^{I} \lambda_{k, t}^{i} r_{t}^{i}$. 
Equation 5 governs the evolution of wealth shares for given investment strategies. The first term captures the capital gains while the second term describes the change in relative wealth as resulting from the exogenous dividends. Our interpretation of the dynamics (Eq. 5) is that of a market selection process on a set of investment strategies.

The dynamics (Eq. 5) is well-defined (Evstigneev et al. 2006, Proposition 1) if there is an investor $j$ with $r_{0}^{j}>0$ and $\lambda_{k, t}^{j}>0$ for all $t, s^{t}, k{ }^{1}$ Equation 5 generates a random dynamical system on the simplex $\Delta=\left\{r \in \mathbb{R}^{I} \mid r^{i} \geq 0\right.$, $\left.\sum_{i} r^{i}=1\right\}$. For any initial distribution of wealth $w_{0} \in \mathbb{R}_{+}^{I}$, Eq. 5 defines the path of wealth shares on the event tree with branches $s^{t}$. The initial distribution of market shares is given by $\left(r_{0}^{i}\right)_{i}=\left(w_{0}^{i} / W_{0}\right)_{i}$. The wealth of a strategy $\lambda^{i}$ in any period in time can be derived from its wealth share and the aggregate wealth, defined by Eq. 3, as

$$
w_{t+1}^{i}=\frac{D_{t+1}\left(s^{t+1}\right)}{\lambda_{0}} r_{t+1}^{i} .
$$

The further analysis will be restricted to the case of state-dependent strategies, i.e., $\lambda_{t}^{i}\left(s^{t}\right)=\lambda^{i}\left(s_{t}\right)$ and a stationary process $s_{t}$. Let us denote $\lambda_{t}^{i}:=\lambda^{i}\left(s_{t}\right)$. Hence, summarizing our assumptions over and above the Lucas model, we assume a constant consumption rate that is common among all investors, adapted non-negative portfolio strategies, and stationary dividends. These assumptions reduce the Lucas model to a simple toy model that is nevertheless rich enough to explain important empirical observations, as we show in Section 4. In the context of this financial market model, Evstigneev et al. (2006) identified a unique investment strategy $\lambda^{*}$ which is evolutionary stable. We present a heuristic derivation of this investment strategy here. Assume, for the sake of simplicity of presentation, strategies are slowly varying (nearly constant). Consider the market selection process close to the one-owns-all states. Suppose investment strategy $\lambda^{j}$ owns almost all of the wealth, i.e. $r_{t}^{j} \approx 1$. Then it determines prices in the sense that $p_{k, t} \approx \lambda_{k, t}^{j}$ and $p_{k, t+1} \approx \lambda_{k, t+1}^{j}$. By assumption we also have $\lambda_{k, t+1}^{j} \approx \lambda_{k, t}^{j}$. Then Eq. 4 yields

$$
\begin{aligned}
r_{t+1}^{i} & \approx \sum_{k=1}^{K}\left(\lambda_{0} d_{k}\left(s_{t+1}\right) \frac{\lambda_{k, t}^{i}}{\lambda_{k, t}^{j}}+\lambda_{k, t+1}^{i}\right) r_{t}^{i} \\
& =\left(1-\lambda_{0}+\lambda_{0} \sum_{k=1}^{K} d_{k}\left(s_{t+1}\right) \frac{\lambda_{k, t}^{i}}{\lambda_{k, t}^{j}}\right) r_{t}^{i} .
\end{aligned}
$$

\footnotetext{
${ }^{1}$ Note that a strategies that could go short, i.e., allowing that $\lambda_{k, t}^{j}<0$ for some $k$, cannot be evolutionary stable since there always exists a configuration of rival strategies that make it bankrupt, leading to extinction.
} 
The exponential growth rate of strategy $\lambda^{i}$ s market share at $\lambda^{j}$-prices can be inferred from this equation. It is given by

$$
g_{\lambda^{j}}\left(\lambda^{i}\right)=\mathbb{E} \ln \left[1-\lambda_{0}+\lambda_{0} \sum_{k=1}^{K} d_{k}(s) \frac{\lambda_{k}^{i}(s)}{\lambda_{k}^{j}(s)}\right]
$$

where $\mathbb{E}$ denotes expected value with respect to the distribution on the set of states of nature $S$.

Evstigneev et al. (2006) establish the following result:

Theorem 1 (Evolutionary Stable Markets) Suppose the states of the world $s_{t}$ follow a stationary Markov process. Then the investment strategy $\lambda^{*}$, defined by

$$
\lambda_{k, t}^{*}=\lambda_{0} \mathbb{E}_{t} \sum_{u=1}^{\infty}\left(1-\lambda_{0}\right)^{u} d_{k}\left(s_{t+u}\right), \quad k=1, \ldots, K
$$

is the only investment strategy that is locally stable against any other investment strategy. More precisely, $g_{\lambda^{*}}(\lambda)<0$ and $g_{\lambda}\left(\lambda^{*}\right)>0$ for all $\lambda \neq \lambda^{*}$.

Here $\mathbb{E}_{t}=\mathbb{E}\left(\cdot \mid s_{t}\right)$ is the conditional expectation.

This result shows that there is always a tendency for the wealth process to converge to the $\lambda^{*}$-investor. Any other composition of the market can be invaded by some strategy growing faster than the incumbent strategy; only if $\lambda^{*}$ governs the market then no further successful invasion is possible. The wealth dynamics implies that relative asset prices $p_{k, t}$ will converge to the process $\lambda_{t}^{*}$.

The above result assumes that investment strategies are distinct across investors. How can one analyze the case in which, for instance, more than one investor adopts the $\lambda^{*}$ strategy? Fortunately, even the general case of investors pursuing the same portfolio strategy is straightforward: Since the relative wealth of two investors with the same portfolio strategy is fixed over time, it is equivalent to assume that investors with the same strategy set up a fund with claims equal to their initial share.

The stability result, Theorem 1, highlights the wisdom in the following comment of the fathers of value investment: Graham and Dodd (1934, page 36) state "We do not believe that short-run price movements-the day to day or the month-to-month variations-are a valid or profitable concern for the security analyst."

\section{Equilibrium with a representative agent}

The evolutionary stable investment strategy can also be obtained as an equilibrium within a standard representative agent model with a stochastic discount factor. This agent is a rational expected utility maximizer. Of course this approach lacks an 'out-of-equilibrium' dynamics. The finding rests on the observation that any arbitrage free process of asset prices can be represented by some stochastic discount factor of some utility function, Harrison and Kreps 
(1979). Since there is no arbitrage in our model one should thus be able to represent asset prices as the outcome of a utility optimization problem. The following theorem assets that the asset prices derived from the investment strategy $\lambda^{*}$ can also be generated in an economy with a representative investor who maximizes discounted expected utility and possesses a constant relative risk aversion of 1 . This result connects our findings to asset pricing based on log-optimal investing. Following Kelly (1956) and Breiman (1961) an impressive literature including Algoet and Cover (1988), Cover $(1984,1991)$ has evolved in which log-optimal portfolios are characterized for various exogenous return processes. See the recent book edited by MacLean et al. (2011) for a full account of this literature. In particular Long (1990) has shown that the return of the log-optimal portfolio can be used to replace the risk free rate in discounted expected dividend pricing. Theorem 2 shows how the log-optimal pricing rule looks like when all asset returns are stripped down to the dividend processes. The unique pricing factor is then given by the relative dividends.

Theorem 2 (Stochastic Discount Factor) Suppose a representative investor with constant relative risk aversion equal to 1 invests in $k=1, \ldots, K$ stocks and uses the residual income for his consumption. Then, denoting his discount factor by $\beta$, the stock prices satisfy

$$
p_{k, t}=\frac{P_{k, t}}{\sum_{n} P_{n, t}}=\frac{1-\beta}{\beta} \mathbb{E}_{t}\left[\sum_{\tau=t+1}^{\infty} \beta^{\tau-t} \frac{D_{k, \tau}}{D_{\tau}}\right]
$$

The stochastic discount factor associated with the standard moment condition with respect to the return of the market portfolio $R_{t}$,

$$
1=\mathbb{E}\left[\delta_{t, t+\tau} R_{t+\tau}\right]
$$

is given by

$$
\delta_{t, t+\tau}=\beta^{\tau} \frac{D_{t}}{D_{t+\tau}}, \quad t=0,1, \ldots, \tau=1,2, \ldots
$$

Proof It is well known that

$$
P_{k, t}=u^{\prime}\left(c_{t}^{*}\right)^{-1} \beta \mathbb{E}\left[u^{\prime}\left(c_{t+1}^{*}\right)\left(D_{k, t+1}+P_{k, t+1}\right)\right]
$$

for all $t$ and $k$ follows from the first order condition of an expected utility maximizer choosing among $k=1, \ldots, K$ assets. Furthermore, in equilibrium we have $c_{t}^{*}=D_{t}$ for all $t$. Substituting $u^{\prime}\left(c_{t}^{*}\right)=c_{t}^{*-1}$ (i.e. the agent's preferences are described through the instantaneous utility $u(c)=\ln (c)$ ) gives

$$
P_{k, t}=D_{t} \beta \mathbb{E}_{t}\left[\left(D_{k, t+1}+P_{k, t+1}\right) / D_{t+1}\right]
$$


Forward iteration gives

$$
P_{k, t}=D_{t} \mathbb{E}_{t}\left[\sum_{\tau=t+1}^{\infty} \beta^{\tau-t} \frac{D_{k, \tau}}{D_{\tau}}\right]
$$

Summing over all assets, we obtain

$$
P_{t}=\sum_{k=1}^{K} P_{k, t}=D_{t} \sum_{\tau=t+1}^{\infty} \beta^{\tau-t}=\frac{\beta D_{t}}{1-\beta}
$$

Finally, combining Eqs. 12 and 13 gives Eq. 9.

Equation 10 is equivalent to

$$
P_{t}=\beta^{\tau} \mathbb{E}\left[\frac{D_{t}}{D_{t+\tau}}\left(P_{t+\tau}+D_{t+\tau}\right)\right]
$$

which is immediate from Eq. 13.

The result shows that stochastic discount factors can rationalize the asset prices obtained in our evolutionary finance model. The stochastic discount factors however are not defined outside the $\lambda^{*}$-equilibrium. Thus Theorem 1 can be seen as a justification for Theorem 2. Indeed the asset pricing model (Eq. 11) is frequently estimated at the equilibrium by using a first-order Taylor series approximation (log-linearization), see, e.g., Campbell and Cochrane (1999). ${ }^{2}$ The evolutionary process allows for describing a stable dynamics converging to the pricing relation given in Theorem 2 .

\section{Implications for the value premium puzzle}

In this section we derive two testable hypotheses from the theoretical results obtained for the evolutionary finance model. To test the model empirically we use constituents of the Dow Jones Industrial Average (DJIA). ${ }^{3}$ The predictions follow from the stability properties of the wealth dynamics. They may help to explain why on long-term averages stock markets look quite rational while severe departures are possible in the short- and medium-term. The particular application of this line of thought is the value premium puzzle. First, relative market capitalizations and relative dividend payments should exhibit a strong relation in cross sections, i.e. the evolutionary asset pricing benchmark should be meaningful. Second, deviations from this benchmark should systematically decrease over time, i.e. the benchmark should be stable. From an evolutionary perspective, the value premium puzzle ceases being a puzzle if both hypotheses hold.

\footnotetext{
${ }^{2} \mathrm{We}$ are grateful to an anonymous referee for pointing this out.

${ }^{3}$ Data are taken from CRSP.
} 
Hypothesis 1 (Market Capitalizations are Determined by $\lambda^{*}$ ) According to Theorem 1, the relative market valuations of firms should be given by the strategy $\lambda^{*}$. This investment strategy prescribes to divide wealth across assets proportional to the present expected value of their (relative) future dividend payoffs which is given by

$$
p_{k, t}=\lambda_{k, t}^{*}=\lambda_{0} \mathbb{E}_{t} \sum_{u=1}^{\infty}\left(1-\lambda_{0}\right)^{u} d_{k}\left(s_{t+u}\right)
$$

The relative market capitalization of a firm is simply calculated from the stock price and the number of shares issued for all firms in the sample. How to determine the relative fundamental value however is less straightforward and, obviously, leaves the econometrician with many options. Rather than attempting to formulate a specific model to calculate the future expected values, we take as a proxy for $\lambda_{k, t}^{*}$ the current relative dividend $d_{k, t}$ of all firms that were listed in DJIA for at least two subsequent years during the period under study. The joint hypothesis tested is that in the linear cross-sectional regression

$$
p_{k, t}=a_{0}(t) d_{k, t}+a_{1}(t)+\varepsilon_{t}, \quad k=1, \ldots, K
$$

$a_{0}(t)>0$ and $a_{1}(t)=0$ for $t=1979, \ldots, 2009 . \varepsilon_{t}$ is the error term. Notice that substituting $a_{0}(t)=\lambda_{0} \mathbb{E}_{t} \sum_{u=1}^{\infty}\left(1-\lambda_{0}\right)^{u}$ relates Eqs. 15 and 16. If this relation holds then, in each year, the relative market capitalization of a firm depends linearly on its current relative dividend payment.

Hypothesis 2 (Convergence of Market Capitalizations to $\lambda^{*}$ ) The convergence of asset prices to the Kelly prices $\lambda^{*}$ is a consequence of the market dynamics. This dynamics implies that (small) deviations from the benchmark $\lambda_{k, t}^{*}$ should vanish over time. The empirical benchmark is provided by the valuation derived in Hypothesis 1, that is

$$
\lambda_{k, t}^{*}=a_{0}(t) d_{k, t}+a_{1}(t),
$$

where $a_{0}(t)$ and $a_{1}(t)$ denote the estimated values. Suppose there is one $\lambda_{t}^{*}$ investor and a mutant investment strategy $\mu_{t}$ representing all the other investors in the market. Exponentially fast convergence of the Kelly investor's wealth share $r_{t}^{*} \rightarrow 1$ can be expressed as $\left[1-r_{t+1}^{*}\right]=L_{t}\left[1-r_{t}^{*}\right]$ with some random variable $L_{t}$, with $E \ln L_{t}<0$. This parameter is determined by the exponential of the logarithmic growth rate $g_{\lambda^{*}}(\mu)$ as defined in Eq. 7. Since

$$
p_{k, t}=\lambda_{k, t}^{*} r_{t}^{*}+\mu_{k, t}\left(1-r_{t}^{*}\right)
$$

one obtains (after some elementary calculations) the relation

$$
\left[\lambda_{k, t+1}^{*}-p_{k, t+1}\right]=L_{t} \frac{\lambda_{k, t+1}^{*}-\mu_{k, t+1}}{\lambda_{k, t}^{*}-\mu_{k, t}}\left[\lambda_{k, t}^{*}-p_{k, t}\right]
$$


Assuming that the relative position of $\mu_{t}$ to $\lambda_{t}^{*}$ is approximately the same between two consecutive time periods, i.e., assuming $\lambda_{k, t}^{*}-\mu_{k, t} \approx \gamma_{k}$, which holds, e.g., with time constant strategies, we formalize our hypothesis as follows. Between any two consecutive years, $t$ and $t+1, t=1981, \ldots, 2008$, the linear regression

$$
\left[\lambda_{k, t+1}^{*}-p_{k, t+1}\right]=a(t)\left[\lambda_{k, t}^{*}-p_{k, t}\right]+\epsilon_{k, t}, \quad k=1, \ldots, K
$$

has a least-squares estimator $0<a(t)<1$.

The empirical results are summarized in Tables 1 and 2. Hypothesis 1 on the relevance of the Kelly rule as a pricing benchmark (for the relative valuation of firms) is supported by the data. In all but 3 years of the sample the coefficient $a_{0}(t)$ is significantly positive at the $5 \%$ level. In addition, the coefficients $a_{1}(t)$ are small, and not significantly different from zero in $2 / 3$ of the sample. The adjusted $R^{2}$ values indicate that a considerable amount of the variation in the data is explained by the model, see Table 1 .

Hypothesis 2 on the convergence of relative market capitalization towards the benchmark is tested in Table 2. Columns $2-4$ contain coefficients, P-values

Table 1 Results on comparison of asset prices with the Kelly benchmark in cross sections (last trading day in a given year $t$ )

\begin{tabular}{|c|c|c|c|c|c|}
\hline Year $t$ & $a_{0}(t)$ & $\mathrm{P}$-value & $a_{1}(t)$ & P-value & $R^{2}$ adj. \\
\hline 1979 & 0.974 & 0.000 & 0.001 & 0.810 & 0.933 \\
\hline 1980 & 0.947 & 0.000 & 0.002 & 0.608 & 0.964 \\
\hline 1981 & 0.854 & 0.002 & 0.005 & 0.376 & 0.912 \\
\hline 1982 & 0.864 & 0.143 & 0.005 & 0.682 & 0.717 \\
\hline 1983 & 0.898 & 0.116 & 0.004 & 0.750 & 0.740 \\
\hline 1984 & 0.964 & 0.042 & 0.001 & 0.888 & 0.802 \\
\hline 1985 & 0.978 & 0.027 & 0.001 & 0.928 & 0.803 \\
\hline 1986 & 0.866 & 0.000 & 0.005 & 0.194 & 0.890 \\
\hline 1987 & 0.833 & 0.000 & 0.006 & 0.050 & 0.900 \\
\hline 1988 & 0.855 & 0.000 & 0.005 & 0.196 & 0.920 \\
\hline 1989 & 0.654 & 0.000 & 0.012 & 0.001 & 0.652 \\
\hline 1990 & 0.833 & 0.000 & 0.006 & 0.043 & 0.844 \\
\hline 1991 & 0.726 & 0.000 & 0.010 & 0.023 & 0.689 \\
\hline 1992 & 0.619 & 0.001 & 0.013 & 0.002 & 0.616 \\
\hline 1993 & 0.691 & 0.015 & 0.011 & 0.133 & 0.766 \\
\hline 1994 & 0.679 & 0.005 & 0.011 & 0.075 & 0.739 \\
\hline 1995 & 0.710 & 0.002 & 0.010 & 0.088 & 0.752 \\
\hline 1996 & 0.750 & 0.002 & 0.009 & 0.164 & 0.713 \\
\hline 1997 & 0.822 & 0.002 & 0.006 & 0.352 & 0.715 \\
\hline 1998 & 0.799 & 0.002 & 0.007 & 0.340 & 0.631 \\
\hline 1999 & 0.965 & 0.000 & 0.001 & 0.864 & 0.692 \\
\hline 2000 & 0.643 & 0.001 & 0.012 & 0.078 & 0.547 \\
\hline 2001 & 0.520 & 0.001 & 0.017 & 0.044 & 0.343 \\
\hline 2002 & 0.515 & 0.000 & 0.017 & 0.027 & 0.365 \\
\hline 2003 & 0.611 & 0.000 & 0.013 & 0.004 & 0.533 \\
\hline 2004 & 0.283 & 0.709 & 0.024 & 0.132 & 0.350 \\
\hline 2005 & 0.690 & 0.000 & 0.010 & 0.005 & 0.637 \\
\hline 2006 & 0.705 & 0.000 & 0.010 & 0.003 & 0.691 \\
\hline 2007 & 0.617 & 0.006 & 0.013 & 0.010 & 0.467 \\
\hline 2008 & 0.731 & 0.033 & 0.009 & 0.261 & 0.412 \\
\hline 2009 & 0.669 & 0.000 & 0.011 & 0.014 & 0.590 \\
\hline
\end{tabular}


of two-sided t-tests and adjusted $R^{2}$ 's of the regression $v_{k, t+1}=a(t) v_{k, t}+\epsilon_{k, t}$, where $v_{k, t}=\lambda_{k, t}^{*}-p_{k, t}$, cf. Eq. 18. All coefficients are greater than zero, and all but 9 are less than 1 . A coefficient $a(t)>1$ implies divergence from the benchmark from the current to the next year. The nine 'no value' years in our sample are 1981, 1982, 1991, 1996, 1997, 1998, 2001, 2007 and 2008, and include the famous bubble years of the late nineties. However, a t-test across all years of the null hypothesis that $a(t)=1$ is rejected at the $5 \%$ level (P-value 0.034), and the null hypothesis that $a(t)=0$ is rejected at any level of significance (P-value 0.000).

It is well-known that regression models such as Eq. 18 may suffer from spurious mean reversion. We therefore perform a supplementary test of Hypothesis 2 on the convergence of asset prices to the $\lambda^{*}$ benchmark. For each year $t$, we first regress $\log \left(p_{k, t}\right)$ on $\log \left(d_{k, t}\right)$ as in Eq. 16, and calculate the (negative) residuals $v_{k, t}=\hat{\lambda}_{k, t}-\log \left(p_{k, t}\right)$, where $\hat{\lambda}_{k, t}$ is the the predicted log

Table 2 Results on the convergence of asset prices to the $\lambda^{*}$ benchmark from year $t$ to $t+1$

Columns 2-4 contain coefficients, White-corrected P-values and adjusted $R^{2}$ s of the regression 18. Column 5 contains annual returns of a self-financing strategy which invests in each asset $k$ proportionally to the negative residuals from a regression of $\log$ relative values on $\log$ relative dividends at time $t$

\begin{tabular}{|c|c|c|c|c|}
\hline \multirow[b]{2}{*}{ Year $t$ to $t+1$} & \multicolumn{3}{|c|}{ Regression results } & \multirow{2}{*}{$\begin{array}{l}\text { Annual } \\
\text { return }\end{array}$} \\
\hline & $a(t)$ & P-value & $R^{2}$ adj. & \\
\hline 1979-1980 & 0.545 & 0.105 & 0.532 & 0.033 \\
\hline 1980-1981 & 1.261 & 0.000 & 0.767 & 0.074 \\
\hline 1981-1982 & 1.899 & 0.000 & 0.868 & 0.010 \\
\hline 1982-1983 & 0.965 & 0.000 & 0.966 & 0.177 \\
\hline 1983-1984 & 0.868 & 0.000 & 0.942 & 0.084 \\
\hline 1984-1985 & 0.969 & 0.000 & 0.936 & 0.110 \\
\hline 1985-1986 & 0.489 & 0.002 & 0.642 & 0.097 \\
\hline 1986-1987 & 0.818 & 0.000 & 0.759 & 0.069 \\
\hline 1987-1988 & 0.769 & 0.000 & 0.826 & 0.040 \\
\hline 1988-1989 & 0.866 & 0.129 & 0.211 & -0.015 \\
\hline 1989-1990 & 0.498 & 0.051 & 0.450 & -0.095 \\
\hline 1990-1991 & 1.159 & 0.000 & 0.671 & 0.146 \\
\hline 1991-1992 & 0.951 & 0.000 & 0.820 & 0.046 \\
\hline 1992-1993 & 0.521 & 0.035 & 0.445 & 0.088 \\
\hline 1993-1994 & 0.959 & 0.000 & 0.829 & -0.027 \\
\hline 1994-1995 & 0.945 & 0.000 & 0.900 & 0.017 \\
\hline 1995-1996 & 1.076 & 0.000 & 0.922 & -0.019 \\
\hline 1996-1997 & 1.028 & 0.000 & 0.912 & -0.065 \\
\hline 1997-1998 & 1.016 & 0.000 & 0.750 & -0.138 \\
\hline 1998-1999 & 0.901 & 0.000 & 0.754 & -0.095 \\
\hline 1999-2000 & 0.583 & 0.024 & 0.783 & 0.151 \\
\hline 2000-2001 & 1.166 & 0.000 & 0.858 & -0.068 \\
\hline 2001-2002 & 0.866 & 0.000 & 0.863 & 0.108 \\
\hline 2002-2003 & 0.731 & 0.000 & 0.783 & 0.059 \\
\hline 2003-2004 & 0.391 & 0.323 & 0.074 & 0.067 \\
\hline 2004-2005 & 0.304 & 0.054 & 0.144 & -0.003 \\
\hline 2005-2006 & 0.867 & 0.000 & 0.836 & 0.123 \\
\hline 2006-2007 & 1.248 & 0.000 & 0.827 & 0.039 \\
\hline 2007-2008 & 1.013 & 0.000 & 0.656 & -0.030 \\
\hline 2008-2009 & 0.230 & 0.095 & 0.117 & 0.035 \\
\hline Mean $(\mu)$ & 0.863 & & & 0.034 \\
\hline Std. dev. & 0.335 & & & 0.078 \\
\hline $\operatorname{Pr}(\mu=0)$ & 0.000 & & & 0.025 \\
\hline $\operatorname{Pr}(\mu=1)$ & 0.034 & & & \\
\hline
\end{tabular}


value of firm $k$ at time $t{ }^{4}$ We then construct a self-financing portfolio by going long or short in each asset $k$ in proportion to the residuals $v_{k, t}$ over the period $t$ to $t+1$. If Hypothesis 2 holds, these $\hat{\lambda}$-portfolios should yield a positive return on average.

Column 5 of Table 2 contains the results. The mean return (including dividends) of the $\hat{\lambda}$ portfolios is $3.4 \%$ per year, and the null hypothesis of zero returns is comfortably rejected at the $5 \%$ level (P-value 0.025$)$. Interestingly, the $\hat{\lambda}$ portfolios have negative returns during the dot-com bubble of the late nineties, but avoid large losses during the subsequent downturn in 2000-2002, as well as during the financial market crisis of 2008.

\section{Conclusion}

This paper offered an explanation of the value premium puzzle from an evolutionary perspective. The results derived in the evolutionary finance model by Evstigneev et al. (2006, 2008) (see also Hens and Schenk-Hoppé 2005) suggest a cross-sectional relation of relative market capitalization and relative dividends. The evolutionary model also provides a formal argument why deviations from this benchmark entail predictability of returns. The empirical evidence obtained in this paper supports the evolutionary explanation of excess returns from value investment.

While the cross-sectional relation could also be seen as resulting from an evaluation based on a representative agent with expected logarithmic utility, our explanation goes beyond the standard economic argument because we explicitly model the dynamics of asset prices for any market situation (i.e. 'off the representative agent equilibrium'). Our explanation is based on the fact that the value strategy of investing proportional to expected relative dividends has the highest growth rate against itself and is the only strategy with this property. Any other market valuation of assets is vulnerable to the invasion of strategies in the sense that the invaders grow against the incumbent strategies. This dynamics ensures the convergence of asset prices to this fundamental value. In the course of convergence the value strategy enjoys the highest growth of external wealth through dividend payments; an observation closely linked to Graham and Dodd (1934).

Our findings highlight that the simple logic of evolution and market selection can successfully compete with more sophisticated arguments that have been made recently to explain the value premium puzzle.

Acknowledgements Financial support by the National Centre of Competence in Research "Financial Valuation and Risk Management" is gratefully acknowledged. Terje Lensberg and Klaus Reiner Schenk-Hoppé also thank the Norwegian Finance Market Fund for financial support (project "Stability of Financial Markets: An Evolutionary Approach").

\footnotetext{
${ }^{4}$ In those years where dividends are zero for one or more firms in the DJIA index, we translate each $d_{k, t}$ by +0.001 to obtain valued numbers from the $\log$ function.
} 


\section{References}

Algoet PH, Cover TM (1988) Asymptotic optimality and asymptotic equipartition properties of log-optimum investment. Ann Probab 16:876-898

Basu S (1977) The investment performance of common stocks in relation to their price to earnings ratios: a test of the efficient market hypothesis. J Finance 32:663-682.

Basu S (1983) The relationship between earnings yield, market value, and return for NYSE common stocks: further evidence. J Financ Econ 12:129-156.

Breiman L (1961) Optimal gambling systems for favorable games. Fourth Berkeley Symposium on Mathematical Statistics and Probability 1:65-78

Campbell JY (1999) Asset prices, consumption and the business cycle. In: Taylor J, Woodford M (eds.) Handbook of Macroeconomics, vol 1. North-Holland, Amsterdam, pp 1231-3103

Campbell JY, Cochrane JH (1999) By force of habit: a consumption-based explanation of aggregate stock market behavior. J Polit Econ 107:205-251

Cover T (1984) An algorithm for maximizing expected log-investment return. IEEE Trans Inf Theory 30:369-373

Cover T (1991) Universal portfolios. Math Financ 1:1-29

Davis JL, Fama EF, French KR (2000) Characteristics, covariances, and average returns: 1929 to 1997. J Finance 55:389-406

Evstigneev I, Hens T, Schenk-Hoppé KR (2006) Evolutionary stable stock markets. Econ Theory 27:449-468

Evstigneev I, Hens T, Schenk-Hoppé KR (2008) Globally evolutionarily stable portfolio rules. J Econ Theory 140:197-228. doi:10.1016/j.jet.2007.09.005

Fama E, French K (1992) The cross section of expected stock returns. J Finance 47:427-466

Graham B, Dodd DL (1934) Security analysis. McGraw Hill, New York

Hansen LP, Heaton JC, Li N (2008) Consumption strikes back? Measuring long-run risk. J Polit Econ 116:260-302

Harrison JM, Kreps DM (1979) Martingales and arbitrage in multiperiod securities markets. J Econ Theory 2:381-408

Hens T, Schenk-Hoppé KR (2005) Evolutionary stability of portfolio rules. J Math Econ 41:43-66

Kelly JL (1956) A new interpretation of information rate. Bell Syst Tech J 35:917-926

Lettau M, Wachter JA (2007) Why is long-horizon equity less risky? A duration-based explanation of the value premium. J Finance 62:55-92

Long JB (1990) The numeraire portfolio. J Financ Econ 26:29-69

Lucas R (1978) Asset prices in an exchange economy. Econometrica 46:1429-1445

MacLean LC, Thorp EO, Ziemba WT (eds) (2011) The Kelly capital growth investment criterion: theory and practice, world scientific 